T $\begin{aligned} & \text { Revista del instituto de ciencias } \\ & \text { jurídicas de puebla, méxico, año V }\end{aligned}$ NO. 28, JULIO-DICIEMBRE DE 2011, PP. 68-84

\title{
La reforma constitucional de derechos humanos y la transversalización de los derechos*
} The Constitutional Reform of Human
Rights and the Mainstreaming of those Rights

\section{Salvador Felipe Arias Ruelas**}

\section{RESUMEN}

El fin de la Segunda Guerra Mundial trajo consigo una revalorización de las ideas de igualdad, justicia y democracia, lo cual se reflejó en el constitucionalismo europeo de la segunda mitad del siglo xx y posteriormente en muchas de las Constituciones de Iberoamérica, introduciendo distintas obligaciones a los Estados en cuanto a la protección de los derechos fundamentales. En el presente artículo, el autor plantea que, a pesar de que el constitucionalismo mexicano ha tenido una evolución particular, con las reformas en materia de derechos humanos introducidas a la Constitución mexicana recientemente, se incorpora una nueva forma de entender, interpretar y aplicar los derechos fundamentales en México, a través de figuras como la vinculación de los poderes públicos a los derechos fundamentales, la comprensión de la doble dimensión de los derechos fundamentales y la ubicación de valores en la Constitución que expresan los principios del Estado democrático.

PALABRAS CLAVE: Derechos fundamentales, reforma constitucional, derechos transversales.

\section{ABSTRACT}

The end of the Second World War brought along the revaluation of the ideas of equality, justice and democracy these was reflected in the second half of the twentieth century in the European constitutionalism and later on many Latin American Constitutions, introducing different state obligations protecting fundamental rights. The author of the present article mentions than in the spite of the Mexican constitutionalism has had a particular evolution, whit reforms introduced recently to the Mexican Constitution on the matter of human rights, and incorporates a new way to understand, interpret and apply fundamental rights in Mexico, through figures like the close relationship of the public powers to those rights, the understanding of the double dimension of the fundamental rights and the location values in the Constitution reflect principles of the democratic state.

KEY WORDS: Fundamental rights, constitutional reform, transverse rights.

* Recibido: 18 de mayo de 2011. Aceptado: 8 de junio de 2011.

** Profesor en la Facultad de Derecho de la unAm, México (sfariasr@derecho.unam.mx). 


\section{Sumario}

1. Algunos aspectos del constitucionalismo contemporáneo

2. Particularidades del constitucionalismo mexicano

3. Fuerza normativa de la Constitución

4. Vinculación de todos los poderes a los derechos humanos

5. La doble dimensión de los derechos fundamentales

6. Valores constitucionales

7. Conclusión

\section{Algunos aspectos del constitucionalismo contemporáneo}

El fin de la Segunda Guerra Mundial trajo consigo una revalorización de las ideas de libertad, justicia y democracia, y, por ende, un proceso de consolidación de los derechos humanos tanto a nivel internacional, con proclamación de la Declaración Universal de Derechos Humanos y la posterior creación y desarrollo de los sistemas de protección universal y regionales de derechos humanos, como a nivel interno de los Estados, particularmente a partir de la reconstitucionalización en Europa, que influiría posteriormente de manera decisiva en América Latina.

A lo largo de la segunda mitad del siglo xx se redefinió el papel que ocupaba la Constitución dentro de las sociedades, y creció la influencia del derecho constitucional sobre las instituciones contemporáneas, particularmente a partir de la aproximación de las ideas del constitucionalismo con los ideales democráticos. $^{1}$

El principal referente de esta nueva forma de entender el derecho constitucional es sin duda la Ley Fundamental de Bonn de 1949 (Constitución alemana) y el surgimiento del Tribunal Constitucional Alemán en 1951, no obstante, algunos otros textos constitucionales merecen ser tomados en cuenta como las Constituciones italiana (1947) y francesa (1946). En nuestro ámbito iberoamericano ejercieron fuerte influencia las Constituciones portuguesa (1976) y española (1978), surgidas ambas en la transición de regímenes autoritarios a sistemas democráticos.

Este nuevo constitucionalismo adquirió una singularidad tan acusada que dio lugar al surgimiento de una nueva cultura jurídica que propició el alumbramiento de una teoría del derecho que, en palabras de Prieto Sanchis, "puede resumirse en una idea de escueta formulación, pero de profundas y fecundas

1 Barroso, Luis Roberto. El neoconstitucionalismo y la constitucionalización del derecho, unam, México, 2008, pp. 1 y 2. 
SALVADOR FELIPE ARIAS RUELAS

consecuencias: constitucionalismo de los derechos o, si se prefiere, Constituciones materiales y garantizadas". ${ }^{2}$

En efecto, a partir de este nuevo constitucionalismo europeo, reflejado posteriormente en el iberoamericano, los derechos fundamentales juegan un papel relevante en las sociedades y se les dota de un complejo sistema de garantías de carácter normativo, jurisdiccional e institucional. ${ }^{3}$ Todo ello reforzado con el reconocimiento de la competencia de la comunidad internacional para participar de forma subsidiaria en la protección de los derechos humanos.

Los derechos fundamentales adquieren una posición preferente en el ordenamiento jurídico y, por tanto, una fuerza expansiva en el actual Estado constitucional, esto es, tales derechos deben extenderse tanto en la actuación de los poderes públicos, como en la elaboración, aplicación e interpretación del resto de las normas del ordenamiento jurídico. Este sentido trasversal adquiere vigencia tanto en el deber de los sujetos obligados por los derechos fundamentales para asegurar su cumplimiento, como en la capacidad de los titulares de tales derechos para exigirlos.

Otra cuestión relevante del constitucionalismo desarrollado a partir de la segunda mitad del siglo xx es el reconocimiento o positivización de los valores en el texto constitucional, los cuales incluso imponen a los operadores jurídicos, particularmente a las autoridades, la obligación de procurarlos, garantizarlos y desarrollarlos, lo que implica un límite al poder y discrecionalidad en sus funciones, en virtud que son derechos directamente aplicables que subsanan, corrigen, remueven y eliminan las violaciones y ataques de los que pudieran ser objeto. ${ }^{4}$

Asimismo, las Constituciones plantean un nuevo esquema de relación entre el derecho interno y el derecho internacional, particularmente aquel que se refiere a la protección de los derechos humanos, lo que hace variar los modelos de recepción del segundo en el primero, e incluso se revalora en muchos casos la jerarquía de las normas internacionales en el sistema jurídico de los Estados. ${ }^{5}$

Esta nueva concepción del constitucionalismo, que tuvo como origen Europa, se extendió después a distintos países de lberoamérica, muchos de los cuales promulgaron nuevas Constituciones, una vez superados largos y dolorosos periodos de autoritarismo y en la transición hacia esquemas de organización más democráticos. Entre los Estados que se dieron un nuevo orden constitucional se

\footnotetext{
2 Prieto Sanchis, Luis. "El constitucionalismo de los derechos", en Carbonell, Miguel (ed.). Teoría del neoconstitucionalismo, Trotta, Madrid, 2007.

3 Cfr. Pérez luño, Antonio Enrique. Los derechos fundamentales, 7a. ed., Tecnos, Madrid, 1998, pp. 66-104.

4 Torres del Moral, Antonio. Principios de derecho constitucional español, 4a. ed., Universidad Complutense de Madrid, Madrid, 1998, pp. 56 y 57.

${ }^{5}$ Cfr . Rey Cantor, Ernesto. Control de convencionalidad de las leyes y derechos humanos, Porrúa-ImDPC, México, 2008, pp. LVII-LXXIV.
} 
encuentra Brasil (1988), Colombia (1991), Paraguay (1992), Argentina (1994), Venezuela (1999), Ecuador (2008), Bolivia (2009).

\section{Particularidades del constitucionalismo mexicano}

La evolución constitucional en México ha tenido un desarrollo particular, la Constitución mexicana de 1917 es una de las más antiguas del mundo, en virtud de que, según lo señala el maestro Jorge Carpizo, "ha tenido la capacidad de reformarse porque se ha ido adecuando a la realidad; si no lo hubiera hecho así, le hubiera quedado muy estrecha a esa realidad y ésta la hubiera hecho añicos”. ${ }^{6}$

Cabe recordar además que la idea de Venustiano Carranza al convocar a un Congreso Constituyente fue la de reformar la Constitución de 1957, y no la de crear un nuevo texto constitucional, incluso el título oficial original de la actual quedó así: "Constitución Política de los Estados Unidos Mexicanos que reforma la del 5 de febrero de 1857".

Desde luego, en la realidad no se trató de una simple reforma, sino que se elaboró una nueva Constitución, que fue incluso la primera en incluir derechos sociales, pero conservó en buena medida la estructura de la Constitución de 1857.

En materia de derechos fundamentales la Constitución mexicana ha ido actualizándose a partir de diversas reformas, y de esta forma se han ido reconociendo en su texto cada vez más derechos, que se adaptan a las nuevas condiciones de la sociedad mexicana, a los avances científicos y tecnológicos, así como a los postulados del derecho internacional de los derechos humanos.

Sin embrago, hay quienes plantean que la sistemática utilizada en la declaración de derechos de nuestra Constitución no parece ser la más apropiada, ${ }^{8} \mathrm{e}$ incluso en los últimos años se ha dado, en el ámbito político y en el académico, un intenso debate sobre la pertinencia o no de elaborar un nuevo texto constitucional.

Las reformas a la carta magna en materia de derechos fundamentales han recogido aspectos que ponen al día a nuestro país en cuanto a su respeto, protección y garantía. Cuestiones tales como el reconocimiento de la composición pluricultural de la nación mexicana, la prohibición de discriminación por cual-

${ }^{6}$ Carpizo, Jorge. Nuevos estudios constitucionales, Porrúa, México, 2000, p. 258.

7 Cfr. Rabasa, Emilio 0. "El pensamiento constitucional de Carranza (Análisis de su mensaje del 10. de diciembre de 1916 al presentar su proyecto de Constitución)", en Anuario Mexicano de Historia del Derecho, unam, México, 1995, vol. VII, 1995, pp. 152 y 153.

${ }^{8}$ Cfr. Carbonell, Miguel. "Los derechos fundamentales en la Constitución mexicana. Propuesta de reforma", en Isonomía. Revista de Teoría y Filosofía del Derecho, ITAM, México, No. 14, abril de 2001, pp. 181 y 182. 
quier motivo, la protección del interés superior de las niñas y niños, el derecho de acceso a la información en poder de los poderes públicos, o el reconocimiento de la cultura y el deporte como derechos, son tan sólo algunos de los ejemplos de la evolución constitucional de México en la materia.

El 10 de junio de 2011, después de un largo proceso de análisis y discusión en las cámaras de Diputados y Senadores, que se originó con la presentación de treinta y tres iniciativas de reforma constitucional y un primer proyecto de decreto en abril de 2009, se publicó, en el Diario Oficial de la Federación, la reforma constitucional que modificó la denominación del Capítulo 1, Título Primero, de la Constitución Política de los Estados Unidos Mexicanos y reformó diversos artículos de ésta.

Dicha reforma constitucional, conocida comúnmente como "Reforma constitucional de derechos humanos", ${ }^{9}$ se refiere a cuestiones relacionadas con derechos fundamentales, que indudablemente traerá como consecuencia una forma distinta de entender, aplicar e interpretar tales derechos en el sistema jurídico mexicano.

Concretamente la modificación del párrafo primero, y la adición de los párrafos segundo y tercero ${ }^{10}$ del artículo 10. incorpora a nuestro texto constitucional figuras del constitucionalismo contemporáneo que a nuestro entender inciden de manera definitiva en la protección, defensa y garantía de los derechos fundamentales, y los extiende a las actuaciones de los poderes públicos y en la aplicación e interpretación del resto de las normas del ordenamiento jurídico.

\section{Fuerza normativa de la Constitución}

Se advierte con claridad de la reforma que la Constitución mexicana, particularmente en lo relativo a derechos fundamentales, está investida de plena eficacia,

\footnotetext{
9 Para efectos de este artículo utilizaremos preferentemente el término "derechos fundamentales" por considerarlo 72 más adecuado, no obstante que la reforma en constitucional utiliza la denominación "derechos humanos". Sobre la diferencia entre ambos términos véase Pérez Luño, Antonio Enrique. op. cit., pp. 44-46.

${ }_{10}$ Artículo 10. En los Estados Unidos Mexicanos todas las personas gozarán de los derechos humanos reconocidos en esta Constitución y en los tratados internacionales de los que el Estado Mexicano sea parte, asi como de las garantías para su protección, cuyo ejercicio no podrá restringirse ni suspenderse, salvo en los casos y bajo las condiciones que esta Constitución establece.

Las normas relativas a los derechos humanos se interpretarán de conformidad con esta Constitución y con los tratados internacionales de la materia favoreciendo en todo tiempo a las personas la protección más amplia.

Todas las autoridades, en el ámbito de sus competencias, tienen la obligación de promover, respetar, proteger y garantizar los derechos humanos de conformidad con los principios de universalidad, interdependencia, indivisibilidad y progresividad. En consecuencia, el Estado deberá prevenir, investigar, sancionar y reparar las violaciones a los derechos humanos, en los términos que establezca la ley.
} 
esto es, que sus normas pueden y deben ser aplicadas directamente por los poderes públicos y tienen la capacidad de producir efectos jurídicos.

Ello significa que los derechos fundamentales son origen inmediato de derechos y obligaciones y no meros principios programáticos, ${ }^{11}$ por lo que no requieren de un desarrollo legislativo para tener eficacia jurídica plena. Desde luego que existen situaciones concretas que hacen pertinente un posterior desarrollo legislativo, lo cual debe determinarse en función de las características de las normas constitucionales en cuanto a su eficacia y aplicabilidad. ${ }^{22}$

Esta cuestión que hoy nos puede parecer obvia no siempre ha sido entendida de la misma forma, particularmente en el siglo xIx, la proclamación de los derechos en el texto constitucional operaba como una simple directiva no vinculante para los poderes públicos ${ }^{13}$ ya que no existía una distinción jurídicamente relevante entre la ley y los derechos.

En el caso mexicano, durante una gran parte del siglo XIx, junto al orden constitucional funcionaba paralelamente un sistema legal que no emanaba ni se supeditaba a la Constitución, ${ }^{14}$ por lo que no sólo era inoperante la eficacia normativa de ésta, sino que incluso se ponía en entredicho su estatus de norma suprema.

Incluso en el siglo xx, la Suprema Corte de Justicia de la Nación enfocó su criterio en el sentido de considerar a la Constitución una norma programática que requería un desarrollo legislativo, como se demuestra en la siguiente tesis aislada:

CONSTITUCIÓN, APLICACIÓN DE LOS PRECEPTOS DE LA. Ningún precepto constitucional cuya aplicación exige determinadas reglas, podrá hacerse efectivo en tanto que el legislador no dicte las reglas, y si bien las cuestiones agrarias y obreras, han sido resueltas de acuerdo con los principios de la Constitución, aun en fechas anteriores a la promulgación de las leyes reglamentarias respectivas, éstas han sido excepciones que dispensa la misma Constitución, según precepto contenido en su artículo 11 transitorio. ${ }^{15}$

Posteriormente, la propia Suprema Corte de Justicia de la Nación fue abandonando tal criterio y reconociendo que todas las autoridades ordinarias o de control constitucional están obligadas a aplicar directamente la Constitución,

\footnotetext{
11 Balaguer Callejón, Francisco (coord.). Manual de derecho constitucional, Tecnos, Madrid, vol. ॥, p. 57.

12 En cuanto a las caracteristicas de eficacia y aplicabilidad de las normas constitucionales véase Afonso DA SILVA, José. Aplicabilidad de las normas constitucionales, unam, México, 2003, pp. 67-72.

${ }_{13}$ Zagrebelsky, Gustav. El derecho dúctil, Trotta, Madrid, 1992, p. 49.

14 Rosario Rodriguez, Marcos del. "Análisis de los diversos modos de conceptualización de la supremacia constitucional desde la antigüedad hasta nuestros días", en Rosario Rodriguez, Marcos del (coord.). Supremacía constitucional, Porrúa-IMDPC, México, 2009, p. 82.

${ }_{15}$ Tesis aislada, Semanario Judicial de la Federación, Quinta Época, t. xxxvı, 14 de octubre de 1932, p. 1028.
} 
SALVADOR FELIPE ARIAS RUELAS

particularmente cuando se está en presencia de derechos fundamentales; ${ }^{16}$ la reforma a los párrafos segundo y tercero del artículo 10. constitucional vienen a reforzar esta idea de eficacia normativa de la Constitución, particularmente cuando se refieren a la interpretación de las normas relativas a los derechos humanos y a la obligación de todas las autoridades de promover, respetar, proteger y garantizar dichos derechos.

\section{Vinculación de todos los poderes a los derechos humanos}

Otra de las cuestiones relevantes de la reforma constitucional en materia de derechos humanos es la derivada del párrafo tercero del artículo 10. de la carta magna, donde se agregó una cláusula específica de vinculación de los poderes públicos a los derechos fundamentales.

En el caso mexicano, concretamente se habla de promover, respetar, proteger y garantizar los derechos humanos, lo que impone una obligación al Estado, a través de los distintos poderes públicos, no sólo de abstenerse de lesionar los derechos fundamentales de las personas, sino de tomar medidas de carácter preventivo, que impidan que cualquier persona o grupo pueda vulnerar tales derechos y, de ser el caso, sancionar y reparar su violación.

Este mandato tiene un alcance general para todos los entes públicos que ejercen un poder de imperio derivado de la soberanía del Estado, en el sentido de quedar sujetos por la Constitución para respetar y proteger los derechos fundamentales, lo que implica reconocer la identidad jurídica propia de tales derechos, a partir del texto constitucional. ${ }^{17}$

Esta vinculación de los poderes públicos a los derechos fundamentales no representa sólo un mandato genérico y programático, sino que tiene consecuencias concretas en cada uno de los poderes públicos, que se refleja en obligaciones específicas de abstención y de actuación de cada uno de ellos.

Si bien es cierto que las normas constitucionales tienen una eficacia jurídica directa, también lo es que la mayoría de ellas precisan, en mayor o menor medida, la intervención legislativa para regular sus condiciones de ejercicio. Por ello, la primera consecuencia de la vinculación de los derechos fundamentales para el Legislativo sería precisamente el desarrollo legislativo de éstos.

Corresponde normalmente al Poder Constituyente la tarea de delimitar los derechos fundamentales, esto es, identificar el ámbito protegido por ellos y la naturaleza de esa protección, lo que se conoce como delimitación inmediata,

${ }^{16}$ Silva Meza, Juan N. y Silva Garcia, Fernando. Derechos fundamentales, Porrúa, México, 2009, p. 106.

17 Jiménez Campo, Javier. Derechos fundamentales. Concepto y garantía, Trotta, Madrid, p. 30. 
no obstante, en muchas ocasiones corresponde al legislador ordinario llevar a cabo una delimitación mediata, cuando se le señala implícita o explícitamente la tarea de precisar o culminar la definición o alcance de determinado elemento del derecho.

Por tanto, el legislador queda vinculado por los derechos fundamentales en el sentido de una delimitación y desarrollo posterior, cuando en las normas relativas a éstos la Constitución establece fórmulas tales como: "en los términos que establezca la ley”, "tal y como lo establezca la ley”, "la ley definirá”, "la ley establecerá los mecanismos”, y otras similares.

Incluso, si acudimos al derecho comparado, podemos encontrar en distintos sistemas jurídicos el principio de reserva de le ley en materia de derechos fundamentales, que implica un mandato específico para que tales derechos únicamente puedan ser desarrollados en leyes emanadas del legislador democráticamente electo, imposibilitando el desarrollo de los derechos por otros operadores juridicos. En algunos casos, las leyes de desarrollo de los derechos fundamentales, denominadas leyes orgánicas, tienen un estatus especial en el sistema de fuentes de derecho. ${ }^{18}$

En este tenor, la referida vinculación de los derechos fundamentales al legislador que lo obliga al desarrollo de las leyes abre una importante posibilidad en cuanto a la probable inconstitucionalidad por omisión legislativa en que pudiera incurrir éste cuando la norma fundamental impone o requiere la intervención de la ley, o bien cuando su actuación no cumple satisfactoriamente con las exigencias constitucionales. ${ }^{19}$

Otra faceta de la vinculación del legislador, muy ligada a lo anterior, es la obligación de respetar el contenido esencial de los derechos fundamentales, que implica un límite en el desarrollo de tales derechos. Hay prácticamente unanimidad en la doctrina y en la jurisprudencia de los países occidentales en el sentido de que los derechos fundamentales tienen un carácter limitado, el cual se encuentra normalmente en los derechos de los demás, en otros derechos y bienes constitucionalmente protegidos y en la ley.

La garantía del contenido esencial de los derechos fundamentales se presenta como un límite a la actividad normativa del legislador. Hablar del contenido esencial de los derechos implica que éstos cuentan con un núcleo básico, resis-

\footnotetext{
${ }^{18}$ Respecto a una propuesta en materia de establecimiento de leyes orgánicas en México, sugerimos consultar: SepúlvedA IGUINIz, RicARDo. "Una propuesta para el establecimiento de leyes orgánicas constitucionales en México", en Cuestiones Constitucionales. Revista Mexicana de Derecho Constitucional, unam, México, No. 15, julio-diciembre de 2006, pp. 224-251.

${ }^{19} \mathrm{Cfr}$. Diaz Revorio, Francisco Javier. Interpretación de la Constitución y justicia constitucional, Porrúa-ImDPC, México, 2009, p. 74.
} 
tente a cualquier transformación, que es lo que hace reconocible al derecho en cuestión y que tienen una zona exterior que está expuesta a la evolución y al cambio, en la que no es aplicable el efecto específico de protección.

$\mathrm{Al}$ desarrollar los derechos fundamentales, el legislador no está autorizado a limitar o restringir los derechos fundamentales, y tiene como obligación interpretar y concretar su contenido, así como establecer las condiciones que hagan posible su más pleno ejercicio por parte de las personas. ${ }^{20}$

Desde luego, dicha garantía del contenido esencial no se fijó expresamente en el texto de la Constitución mexicana, no obstante, tal obligación puede advertirse en lo señalado en el párrafo tercero del artículo 10. de la carta magna, lo cual se refuerza con distintas interpretaciones que al respecto ha realizado la Suprema Corte de Justicia de la Nación, como es la siguiente tesis aislada emitida por la Primera Sala del máximo tribunal.

DeREChO A LA IDENTIDAD DE LOS MENORES. Su CONTENIDO. El artículo 7 de la Convención sobre los Derechos del Niño (ratificada por el Estado Mexicano y publicada en el Diario Oficial de la Federación el 25 de enero de 1991) dispone que el niño tiene derecho desde que nace a un nombre, a adquirir una nacionalidad y en la medida de lo posible a conocer a sus padres y a ser cuidado por ellos. En concordancia con lo anterior y conforme al numeral 3 de la Ley para la Protección de los Derechos de Niñas, Niños y Adolescentes (de orden público, interés social y observancia obligatoria para toda la República), son principios rectores de la protección de los menores, entre otros, el del interés superior de la infancia y el de la tutela plena e igualitaria de los derechos humanos y de las garantías constitucionales. En ese tenor, el artículo 22 de dicha Ley establece el derecho a la identidad, el cual se compone por el derecho a tener un nombre y los apellidos de los padres desde que nazca, a tener una nacionalidad y a conocer su filiación y su origen, salvo en el caso que las leyes lo prohíban. Así, el hecho de que el menor tenga la certeza de quién es su progenitor, constituye un principio de orden público que es parte del núcleo esencial del derecho fundamental a la personalidad jurídica, cuya importancia no sólo radica en la posibilidad de solicitar y recibir información sobre su origen, la identidad de sus padres y el conocimiento de su origen genético, sino que a partir de esos elementos puede derivarse, por una parte, su derecho a tener una nacionalidad y, por otra, el derecho a que sus ascendientes satisfagan sus necesidades de alimentación, salud, educación y sano esparcimiento, para su desarrollo pleno e integral ${ }^{21}$ (cursivas añadidas).

${ }_{20}$ Martinez-Pujalte, Antonio-Luis. La garantía del contenido esencial de los derechos fundamentales, Centro de Estudios Constitucionales, Madrid, 1997, p. 141.

${ }_{21}^{21}$ Tesis 1a. cxuI/2007, Semanario Judicial de la Federación y su Gaceta, Novena Época, t. xxVI, julio de 2007, p. 260. Otras tesis relativas al contenido esencial son las siguientes: Tesis 1a. xcvil/2007, Semanario Judicial de la Federación y su Gaceta, Novena Época, t. xxv, mayo de 2007, p. 794; Tesis: 1a. cxul/2007, Semanario Judicial de la Federación y su Gaceta, Novena Época, t. xxvı, julio de 2007, p. 269; Tesis: 2a. xxxv//2007, Semanario Judicial de la Federación y su 
En cuanto a los órganos que desempeñan funciones materialmente jurisdiccionales, la vinculación a los derechos fundamentales también tiene algunos aspectos específicos. En primer lugar, en forma genérica implica la obligación de éstos de asegurar el acceso a la jurisdicción del Estado y el respeto a los principios del debido proceso.

Desde luego, el aspecto de la vinculación a los derechos fundamentales tiene distintos aspectos tratándose de jueces ordinarios o de jueces constitucionales. Los primeros tienen en todo momento la posibilidad de hacer una interpretación amplia de los preceptos constitucionales, derivada del principio pro homine establecido en el párrafo segundo del artículo 10. de la carta magna, en el sentido de favorecer en todo tiempo la protección más amplia para la persona.

Evidentemente los jueces constitucionales tienen un papel destacado en la defensa y protección de los derechos humanos plasmados en los textos constitucionales y de los tratados internacionales de la materia, ya que les corresponde la aplicación de la mayoría de las garantías constitucionales. ${ }^{22}$

También tiene relevancia en el caso de la vinculación a los jueces el sistema de control de la constitucionalidad que cada en orden jurídico opere. En cuanto al caso mexicano, quizá éste es uno de los aspectos más sobresalientes de la reforma constitucional, y que refleja de mejor manera la aplicación transversal de los derechos fundamentales.

A lo largo de la historia ha tenido lugar un amplio debate sobre el sistema de control de la constitucionalidad que debe operar en México. ${ }^{23}$ Destacados juristas plantearon posiciones encontradas sobre la conveniencia de un sistema de control concentrado o un sistema de control difuso, prevaleciendo en los últimos tiempos en la jurisprudencia de la Suprema Corte de Justicia de la Nación la interpretación favorable al control concentrado, como se advierte en la siguiente tesis del Pleno:

Gaceta, Novena Época, t. xxv, mayo de 2007, p. 1183; Tesis 2a. xxxv1/2007, Semanario Judicial de la Federación y su Gaceta, Novena Época, t. xxV, mayo de 2007, p. 1183.

${ }^{22}$ En este caso, entendemos garantías constitucionales de acuerdo a la definición formulada por el maestro Héctor FIX-ZAmudio, en el sentido de que se trata de medios juridicos de naturaleza predominantemente procesal, que están dirigidos a la reintegración del orden constitucional cuando el mismo ha sido desconocido o violado por los propios órganos del poder, y los instrumentos protectores de la Constitución no han sido suficientes para lograr el respeto y el cumplimiento de las disposiciones constitucionales. Véase Fix-Zamudio, Héctor. Estudio de la defensa de la Constitución en el ordenamiento mexicano, Porrúa, México, 2011, pp. 10-12.

${ }^{23}$ Sobre el debate histórico acerca del sistema de control constitucional véase Sánchez GIL, RuBÉn. "El control difuso de la constitucionalidad en México. Reflexiones en torno a la tesis P./J. 38/2002", en Cuestiones Constitucionales, Revista Mexicana de Derecho Constitucional, México, No. 11, julio-diciembre de 2004, pp. 199-229; Gudiño Pelayo, José DE Jesús. "Lo confuso del control difuso de la Constitución. Propuesta de interpretación del artículo 133", en Revista de la Facultad de Derecho de México, t. Lv, No. 244, 2005, pp. 79-109. 
SALVADOR FELIPE ARIAS RUELAS

Control judicial de la Constitución. Es atribución exclusiva del Poder Judicial de la FedeRACIÓN. La supremacía constitucional se configura como un principio consustancial del sistema jurídico-político mexicano, que descansa en la expresión primaria de la soberanía en la expedición de la Constitución, y que por ello coloca a ésta por encima de todas las leyes y de todas las autoridades, de ahí que las actuaciones de éstas deben ajustarse estrictamente a las disposiciones de aquélla. En este sentido, más que una facultad, la supremacía constitucional impone a toda autoridad el deber de ajustar a los preceptos fundamentales, los actos desplegados en ejercicio de sus atribuciones. Por tanto, si bien es cierto que los tres Poderes de la Unión deben observar la Ley Suprema, no puede afirmarse que por esta razón, las autoridades puedan, por sí y ante sí, en el ejercicio de funciones materialmente jurisdiccionales, examinar la constitucionalidad de sus propios actos o de los ajenos, toda vez que, al respecto, la propia Constitución consagra, en sus artículos 103 y 107, un medio de defensa exprofeso, por vía de acción, como es el juicio de amparo y lo encomienda, en exclusiva, al Poder Judicial de la Federación, sentando las bases de su procedencia y tramitación. ${ }^{24}$

Derivado de la sentencia emitida por la Corte Interamericana de Derechos Humanos sobre el caso "Radilla Pacheco" en contra del Estado mexicano, el presidente de la Suprema Corte de Justicia de la Nación formuló una solicitud al Tribunal Pleno para determinar el trámite que debía darse a dicha sentencia. Ello dio lugar a la resolución dictada por dicha Corte en el expediente 912/2010. ${ }^{25}$

En la citada resolución, la mayoría de los ministros de la Corte abandonan el criterio de control concentrado de la constitucionalidad, para dar paso a uno difuso, o en los términos del considerando 36 de dicha resolución:

[...] Es un sistema que, como hemos visto, es concentrado en una parte y difuso en otra y que permite que sean los criterios e interpretaciones constitucionales, ya sea por declaración de inconstitucionalidad o por inaplicación, los que finalmente fluyan hacia la Suprema Corte para que determine cuál es la interpretación constitucional que finalmente debe prevalecer en el orden jurídico nacional. Puede haber ejemplos de inaplicación que no sean revisables en las vías directas o concentradas de control, pero esto no hace inviable la otra vertiente del modelo general. ${ }^{26}$

Por su relevancia y relación con el tema de la vinculación de los poderes públicos a los derechos humanos, particularmente en cuanto a la interpretación y

${ }^{24}$ Tesis p./J. 73/99, Semanario Judicial de la Federación y su Gaceta, Novena Época, t. x, agosto de 1999, p. 18.

25 Publicada en el Diario Oficial de la Federación el 4 de octubre de 2011. Consultada en linea: http://dof.gob.mx/ nota_detalle.php?codigo $=5212527 \&$ fecha $=04 / 10 / 2011$

${ }^{26}$ Idem. 
aplicación de las normas constitucionales, reproducimos el cuadro incluido en el considerando 36 de la resolución del expediente varios 912/2010. ${ }^{27}$

\section{MODELO GENERAL DE CONTROL DE CONSTITUCIONALIDAD Y CONVENCIONALIDAD}

\begin{tabular}{|c|c|c|c|c|}
\hline $\begin{array}{l}\text { Tipo de } \\
\text { control }\end{array}$ & Órgano y medios de control & $\begin{array}{l}\text { Fundamento } \\
\text { constitucional }\end{array}$ & Posible resultado & Forma \\
\hline Concentrado: & $\begin{array}{l}\text { Poder Judicial de la Federa- } \\
\text { ción (tribunales de amparo): } \\
\text { a) Controversias constitu- } \\
\text { cionales y acciones de in- } \\
\text { constitucionalidad. } \\
\text { b) Amparo indirecto } \\
\text { c) Amparo directo }\end{array}$ & $\begin{array}{l}\text { Artículos 105, } \\
\text { fracciones I y II, } \\
103,107, \text { fracción } \\
\text { VII, y 103, 107, } \\
\text { fracción IX }\end{array}$ & $\begin{array}{l}\text { Declaración de } \\
\text { inconstitucionalidad } \\
\text { con efectos generales } \\
\text { o interpartes. } \\
\text { No hay declaratoria de } \\
\text { inconstitucionalidad }\end{array}$ & Directa \\
\hline $\begin{array}{l}\text { Control por } \\
\text { determinación } \\
\text { constitucional } \\
\text { específica: }\end{array}$ & $\begin{array}{l}\text { a) Tribunal Electoral en } \\
\text { juicio de revisión constitu- } \\
\text { cional electoral de actos o } \\
\text { resoluciones definitivos y } \\
\text { firmes de las autoridades } \\
\text { electorales locales en or- } \\
\text { ganización y calificación de } \\
\text { comicios o controversias en } \\
\text { los mismos } \\
\text { b) Tribunal Electoral del Po- } \\
\text { der Judicial de la Federación }\end{array}$ & $\begin{array}{l}\text { Artículos 41, frac- } \\
\text { ción vı, 99, párrafo } \\
\text { 6, y 99, párrafo } 6\end{array}$ & $\begin{array}{l}\text { No hay declaración } \\
\text { de inconstitucionali- } \\
\text { dad, sólo inaplicación }\end{array}$ & $\begin{array}{c}\text { Directa } \\
\text { e incidental }\end{array}$ \\
\hline Difuso: & $\begin{array}{l}\text { a) Resto de los tribunales } \\
\text { b) Federales: Juzgados de } \\
\text { Distrito y Tribunales Uni- } \\
\text { tarios de proceso federal y } \\
\text { Tribunales Administrativos } \\
\text { c) Locales: Judiciales, admi- } \\
\text { nistrativos y electorales }\end{array}$ & $\begin{array}{l}\text { Artículos 10., 133, } \\
104 \text { y derechos } \\
\text { humanos en } \\
\text { tratados. Artículos } \\
\text { 10., 133, } 116 \text { y de- } \\
\text { rechos humanos } \\
\text { en tratados }\end{array}$ & $\begin{array}{l}\text { No hay declaración } \\
\text { de inconstitucionali- } \\
\text { dad, sólo inaplicación }\end{array}$ & Incidental \\
\hline $\begin{array}{l}\text { Interpretación } \\
\text { más favorable: }\end{array}$ & $\begin{array}{l}\text { Todas los autoridades del } \\
\text { Estado mexicano }\end{array}$ & $\begin{array}{l}\text { Artículo 10. y de- } \\
\text { rechos humanos } \\
\text { en tratados }\end{array}$ & $\begin{array}{l}\text { Solamente interpreta- } \\
\text { ción aplicando la nor- } \\
\text { ma más favorable a las } \\
\text { personas sin inaplica- } \\
\text { ción o declaración de } \\
\text { inconstitucionalidad }\end{array}$ & $\begin{array}{l}\text { Fundamen- } \\
\text { tación y } \\
\text { motivación }\end{array}$ \\
\hline
\end{tabular}

\footnotetext{
27 Idem.
} 
SALVADOR FELIPE ARIAS RUELAS

En el caso de las administraciones públicas, la vinculación a los derechos fundamentales es fácil de advertir, probablemente el Poder Ejecutivo se constituye en el principal sujeto pasivo de las obligaciones que derivan de los distintos derechos, que pueden ser tanto de abstención en el sentido de evitar inferir en la esfera jurídica de los gobernados, como de carácter positivo, particularmente en la prestación de los diversos servicios públicos.

Asimismo, implica una obligación para el Ejecutivo diseñar diagnósticos y planes estatales en materia de derechos humanos, como quedó establecido en la Declaración y Programa de Acción de la Conferencia Mundial sobre Derechos Humanos, ${ }^{28}$ llevada a cabo en Viena en 1993. Esto es, las políticas públicas deben contemplar la aplicación trasversal de los derechos fundamentales en las diversas actividades de las administraciones públicas. ${ }^{29}$

\section{La doble dimensión de los derechos fundamentales}

De acuerdo con la reforma, las normas relativas a los derechos humanos tendrán que ser interpretadas de conformidad con la Constitución y con los tratados internacionales de la materia. Desde nuestro punto de vista, esto implica que las normas que comprenden derechos fundamentales, constitucionales o internacionales, deben informar la actuación de todos los poderes públicos y su contenido debe irradiar al resto del ordenamiento jurídico y constituirse en un criterio para su interpretación y aplicación.

Esto es lo que se conoce como la teoría de la doble dimensión de los derechos fundamentales, a través de la cual se conciben éstos en un primer término en una dimensión subjetiva que consiste en el haz de facultades jurídicas que se le atribuyen al titular del derecho para defender el objeto del derecho fundamental frente a terceros, ${ }^{30}$ pero a la vez se les atribuye una dimensión objetiva, al considerarlos elementos esenciales de un ordenamiento objetivo de la comunidad, en cuanto ésta se configura como un marco de convivencia humana, justa y pacífica. $^{31}$

La dimensión subjetiva de los derechos fundamentales implica reconocer que éstos representan un sistema de valores, y son, por tanto, principios superiores del ordenamiento jurídico en su conjunto que implica un nuevo entendimiento

${ }^{28}$ El texto completo puede consultarse en: http://www.unhchr.ch/huridocda/huridoca.nsf/(Symbol)/A.CONF.157.23. Sp?OpenDocument.

${ }^{29}$ En el caso de México, en el Distrito Federal se publicó, el 30 de mayo de 2011, la Ley del Programa de Derechos Humanos de la Ciudad de México, que establece obligaciones para la planeación con perspectiva de derechos humanos.

30 Silva Meza, Juan N. y Silva Garcia, Fernando. op. cit., p. 136.

31 Cfr. Pérez Luño, Antonio Enrioue. op. cit., p. 26. 
de la actividad a desarrollar por el poder público, ya que éste no es considerado como una amenaza para la libertad del individuo, sino como un garante de la plena efectividad de las normas fundamentales.

La dimensión objetiva trae como consecuencia el llamado efecto de irradiación de los derechos fundamentales, que supone que su contenido se transmite, propaga y difunde en todo el ordenamiento jurídico y deben de servir de criterio básico para la producción normativa y su posterior interpretación y aplicación.

Asimismo, la dimensión objetiva de los derechos fundamentales implica un deber especial de protección de tales derechos, que se traduce en el comportamiento que deben asumir los órganos estatales cuando la conducta de terceros vulnera o pone en peligro los bienes iusfundamentales protegidos de las personas, incluso cuando esa amenaza viene de personas o poderes que no son los destinatarios tradicionales de los derechos fundamentales. ${ }^{32}$

La comprensión de la dimensión objetiva de los derechos fundamentales ha dado lugar a interpretación en cuanto a la eficacia de los derechos fundamentales frente a los particulares, cambiando el modo tradicional de entender que los poderes públicos son los únicos posibles violadores de derechos humanos y que sólo ante la acción de éstos se pueden interponer mecanismos de protección de tales derechos. ${ }^{33}$

La interpretación en cuanto a la dimensión objetiva de los derechos fundamentales no representa algo nuevo en nuestro sistema jurídico. Así, la Primera Sala de la Suprema Corte de Justicia de la Nación emitió un criterio jurisprudencial en estos términos:

lgualdAd. Límites a eSTe PRIncipIo. La Constitución Política de los Estados Unidos Mexicanos establece que todos los hombres son iguales ante la ley, sin que pueda prevalecer discriminación alguna por razón de nacionalidad, raza, sexo, religión o cualquier otra condición o circunstancia personal o social, de manera que los poderes públicos han de tener en cuenta que los particulares que se encuentren en la misma situación deben ser tratados igualmente, sin privilegio ni favor. Así, el principio de igualdad se configura como uno de los valores superiores del orden jurídico, lo que significa que ha de servir de criterio básico para la producción normativa y su posterior interpretación y aplicación, y si bien es cierto que el verdadero sentido de la igualdad es colocar a los particulares en condiciones de poder acceder a derechos reconocidos constitucionalmente, lo que implica eliminar situaciones de desigualdad manifiesta,

\footnotetext{
32 Julio Estrada, Alexel. La eficacia de los derechos fundamentales entre particulares, Universidad Externado de Colombia, Bogotá, 2000, p. 75.

${ }^{33}$ En cuanto a la eficacia de los derechos fundamentales frente a particulares remito a mi artículo: "La eficacia de los derechos fundamentales frente a los particulares", en Gaceta de la Comisión Nacional de los Derechos Humanos, México, No. 147, octubre de 2002, pp. 41-68.
} 
SALVADOR FELIPE ARIAS RUELAS

ello no significa que todos los individuos deban ser iguales en todo, ya que si la propia Constitución protege la propiedad privada, la libertad económica y otros derechos patrimoniales, está aceptando implícitamente la existencia de desigualdades materiales y económicas; es decir, el principio de igualdad no implica que todos los sujetos de la norma se encuentren siempre, en todo momento y ante cualquier circunstancia, en condiciones de absoluta igualdad, sino que dicho principio se refiere a la igualdad jurídica, que debe traducirse en la seguridad de no tener que soportar un perjuicio (o privarse de un beneficio) desigual e injustificado. En estas condiciones, el valor superior que persigue este principio consiste en evitar que existan normas que, llamadas a proyectarse sobre situaciones de igualdad de hecho, produzcan como efecto de su aplicación la ruptura de esa igualdad al generar un trato discriminatorio entre situaciones análogas, o bien, propicien efectos semejantes sobre personas que se encuentran en situaciones dispares, lo que se traduce en desigualdad jurídica ${ }^{34}$ (cursivas añadidas).

\section{Valores constitucionales}

A diferencia de muchas otras, nuestra Constitución no contiene un preámbulo, un rubro de principios generales ni la declaración expresa de cuáles son los valores superiores en los que funda su orden jurídico, no obstante, es claro que nuestra carta magna reconoce, incorpora y protege distintos valores. ${ }^{35}$

En este sentido, la reforma del artículo 10. incorpora aspectos interesantes. En principio, se abandonó la idea del otorgamiento de los derechos por parte del Estado, para señalar que tales derechos solamente se reconocen en la Constitución y los tratados internacionales; asimismo, se señalan las características de universalidad, interdependencia, indivisibilidad y progresividad de los derechos, y quedó establecida la obligación del Estado de prevenir, investigar, sancionar y reparar las violaciones de derechos humanos.

Anteriormente, en 2006, se había incorporado al propio artículo 1o. la prohibición expresa de discriminación por motivo de origen étnico o nacional, el género, la edad, las discapacidades, la condición social, las condiciones de salud, la religión, las opiniones, las preferencias, ${ }^{36}$ el estado civil o cualquiera otra que atente contra la dignidad humana y tenga por objeto anular o menoscabar los derechos y libertades de las personas.

\footnotetext{
${ }^{34}$ Tesis 1a./J.81/2004, Semanario Judicial de la Federación y su Gaceta, Novena Época, t. xx, octubre de 2004, p. 99. ${ }_{35}$ En cuanto a los valores en la Constitución de México, véase MAdRID H., Miguel DE LA. "Los valores en la Constitución mexicana", en Garcia Ramirez, Sergio. Los valores en el derecho mexicano, unam-Fondo de Cultura Económica, México, 1997, pp. 261-292.

${ }^{36}$ La reforma de junio de 2011 cambia el término "preferencias" por "preferencias sexuales".
} 
Otros valores, como la libertad, la justicia, la seguridad, la igualdad, la democracia y la laicidad del Estado, entre otros, se pueden advertir claramente en distintos artículos constitucionales, los cuales han sido recogidos e integrados al orden jurídico nacional no sólo en la actual carta magna, sino en las que la precedieron.

Como se señaló previamente, el constitucionalismo contemporáneo ha reconocido el carácter normativo de los valores insertos en el texto constitucional. La reforma al artículo 10. abre la puerta a una interpretación más amplia de la Constitución, que pudiera dar lugar a la incorporación de los valores como criterios para determinar la adecuación material de las normas del ordenamiento jurídico a la carta magna, lo cual no sería una novedad en la jurisprudencia de nuestro máximo tribunal, como se puede advertir en la siguiente tesis.

\begin{abstract}
INDAGATORIA DE PATERNIDAD. No ES OBSTÁcULO PARA LA MISMA QUE El PRESUNTO PADRE HAYA ESTADO CASADO CON PERSONA DISTINTA A LA MADRE DEL NIÑO, AL MOMENTO DE SU CONCEPCIÓN (ARTíCULO 315 del Código Civll para el Estado de Veracruz, vigente hasta el 7 de octubre de 2010). La restricción al ejercicio del derecho a la identidad de los menores que establece el artículo 315 del Código Civil para el Estado de Veracruz - vigente hasta el 7 de octubre de 2010-, consistente en que al momento de la concepción el padre no haya estado casado con persona distinta a la madre, no se ajusta a los valores y principios que protege la Constitución. No debe ser obstáculo para la indagatoria de paternidad el estado civil del presunto padre, ya que debe prevalecer el derecho del niño a conocer su identidad y ejercer los derechos derivados de ésta frente a la protección de la estabilidad del matrimonio del presunto padre ${ }^{37}$ (cursivas añadidas).
\end{abstract}

\title{
7. Conclusión
}

La Constitución mexicana de 1917 ha sido objeto de diversas reformas y adiciones a efecto de reconocer los derechos fundamentales que reflejan los valores de la sociedad mexicana y que se adaptan al nuevo entorno internacional y a los avances de la ciencia y la tecnología. La reforma en materia de derechos humanos, publicada en junio de 2011, trae además consigo diversos aspectos que implican una forma diferente de comprender, aplicar e interpretar los derechos fundamentales de manera.

Probablemente no sea una reforma completa y definitiva, pero indudablemente introduce aspectos interesantes en el sistema jurídico mexicano, como lo

\footnotetext{
37 Tesis 1a./J. 75/2011, Semanario Judicial de la Federación y su Gaceta, Novena Época, t. xxxiv, septiembre de 2011,
} p. 663. 
SALVADOR FELIPE ARIAS RUELAS

es la cláusula de vinculación de todos los poderes públicos a los derechos fundamentales, lo que implica que en su actuación cotidiana estos derechos deben estar presentes transversalmente, ya que deben constituir criterios para la producción normativa y su posterior interpretación y aplicación.

La reforma posibilita una nueva forma de entendimiento de los derechos fundamentales al momento de ser aplicados o interpretados, integrando aspectos que ya están reflejados en la jurisprudencia de la Suprema Corte de Justicia de la Nación, tales como la doble dimensión de los derechos fundamentales o la ubicación de valores en el texto constitucional con fuerza normativa.

Desde luego, es deseable que la carta magna se ponga al día permanentemente en cuanto al respeto, protección y garantía de los derechos fundamentales, probablemente falte incluir expresamente figuras como la garantía del contenido esencial de los derechos fundamentales y la reserva de ley, e incluso explorar la posibilidad de las leyes orgánicas constitucionales.

No obstante, hoy tenemos en México, derivado de la reforma constitucional, mejores instrumentos para la protección y garantía de los derechos fundamentales, lo cual deberá ser complementado con las leyes que con motivo de dicha reforma tendrá que elaborar el Congreso de la Unión. Mientras tanto, la introducción de las figuras antes señaladas y la nueva forma de recepción de los tratados internacionales en materia de derechos humanos son buenas noticias para los mexicanos y sus derechos. 